\title{
Efeito da nutrição de nitrato na tolerância de plantas de sorgo sudão à salinidade ${ }^{1}$
}

\author{
Effect of nitrate nutrition on tolerance of sudangrass plants to salinity
}

\author{
Alexcyane Rodrigues Feijão ${ }^{2}$, Júlio César Barbosa da Silva ${ }^{3}$, Elton Camelo Marques ${ }^{2}$, José Tarquinio Prisco e $^{4}$ \\ Enéas Gomes-Filho ${ }^{*}$
}

\begin{abstract}
Resumo - O objetivo deste trabalho foi estudar o efeito da nutrição de $\mathrm{NO}_{3}^{-}$no crescimento, nas trocas gasosas e no acúmulo de solutos inorgânicos e orgânicos em plantas de sorgo sudão submetidas à salinidade. As plantas foram cultivadas em meio hidropônico e mantidas em casa de vegetação. $\mathrm{O}$ delineamento experimental foi o inteiramente casualizado, em esquema fatorial $2\left(\mathrm{NO}_{3}^{-}\right.$a $0,5 \mathrm{mM}$ ou $\left.8,0 \mathrm{mM}\right) \times 2(\mathrm{NaCl}$ a $0 \mathrm{mM}$ ou $100 \mathrm{mM})$, com cinco repetições. Os dados foram submetidos à análise de variância e as médias comparadas pelo teste de Tukey a $5 \%$ de significância. A salinidade reduziu a área foliar e a massa seca da parte aérea e das raízes, sendo as plantas nutridas com $\mathrm{NO}_{3}^{-}$a $8,0 \mathrm{mM}$ menos afetadas que aquelas com $\mathrm{NO}_{3}^{-}$a $0,5 \mathrm{mM}$. A condutância estomática, a fotossíntese, a transpiração e a relação entre a concentração interna e externa de $\mathrm{CO}_{2}$ foram aumentadas pela melhor nutrição de $\mathrm{NO}_{3}^{-}$. Os teores de $\mathrm{Na}^{+}$e $\mathrm{Cl}^{-}$foram significativamente aumentados pela salinidade em folhas e em raízes e os de $\mathrm{K}^{+}$foram reduzidos apenas nas raízes. Apesar disso, as plantas nutridas com $\mathrm{NO}_{3}$ a $8,0 \mathrm{mM}$ apresentaram os menores teores de $\mathrm{Na}^{+}$e $\mathrm{Cl}^{-}$nas folhas sob estresse salino. A salinidade aumentou os teores de prolina e $\mathrm{N}$-aminossolúveis e a maior concentração de $\mathrm{NO}_{3}^{-}$no meio favoreceu o acúmulo desses solutos nas raízes de plantas estressadas. Uma adequada nutrição com $\mathrm{NO}_{3}^{-}$foi capaz de reduzir os efeitos deletérios da salinidade nas plantas de sorgo sudão.
\end{abstract}

Palavras-chave - Crescimento. Estresse salino. Nitrogênio. Solutos inorgânicos e orgânicos. Sorghum sudanense.

\begin{abstract}
This work aimed to study the effect of $\mathrm{NO}_{3}^{-}$nutrition on growth, on gas exchange and on inorganic and organic solutes accumulation of sudangrass plants subjected to salinity. Plants were grown in hydroponic medium and kept in a greenhouse. The experiment was a completely randomized design, following a factorial arrangement of $2\left(\mathrm{NO}_{3}{ }^{-}\right.$at $0,5 \mathrm{mM}$ or $8,0 \mathrm{mM}) \times 2(\mathrm{NaCl}$ at $0 \mathrm{mM}$ or $100 \mathrm{mM})$, with five replications. All data were subjected to analysis of variance and the means were compared by Tukey's test at 5\% of significance. Salinity reduced leaf area and dry weight of shoots and roots. However, plants growing in the $8.0 \mathrm{mM} \mathrm{NO}_{3}^{-}$increased more than those growing in $0.5 \mathrm{mM}$. The stomatal conductance, photosynthesis, transpiration and the relationship between internal and external concentration of $\mathrm{CO}_{2}$ were increased by better nutrition $\mathrm{NO}_{3}^{-}$. $\mathrm{Na}^{+}$and $\mathrm{Cl}^{-}$contents were significantly increased by salinity in leaves and roots and the $\mathrm{K}^{+}$content was reduced only in the roots. Nevertheless, plants fed with $8.0 \mathrm{mM} \mathrm{NO}_{3}^{-}$had the lowest contents of $\mathrm{Na}^{+}$and $\mathrm{Cl}^{-}$in leaves under salt stress. Salinity increased proline and amino acid contents and the higher $\mathrm{NO}_{3}^{-}$concentration promoted the accumulation of these solutes in roots of stressed plants. Proper nutrition for $\mathrm{NO}_{3}{ }^{-}$was able to reduce deleterious effects of salinity in sudangrass plants.
\end{abstract}

Key words - Growth. Salt stress. Nitrogen. Inorganic and organic solutes. Sorghum sudanense.

\footnotetext{
* Autor para correspondência

${ }^{1}$ Recebido para publicação em 31/08/2010; aprovado em 31/01/2011

Trabalho submetido e selecionado no primeiro Simpósio Brasileiro de Salinidade realizado de 12-15/10/2010 em Fortaleza, Ceará, Brasil; parte da

Monografia do segundo autor apresentada ao Curso de Ciências Biológicas/UFC

${ }^{2}$ Programa de Pós-Graduação em Bioquímica, CC/UFC, Fortaleza-CE, Brasil, alexcyane_feijao@yahoo.com.br, eltoncmarques@gmail.com

${ }^{3}$ Curso de Ciências Biológicas, CC/UFC, Fortaleza-CE, Brasil, cesarbarbos@yahoo.com.br

${ }^{4}$ Departamento de Bioquímica e Biologia Molecular e Instituto Nacional de Ciência e Tecnologia em Salinidade, CC/UFC, Caixa Postal 6.039,

Fortaleza-CE, Brasil, 60.455-970,jtprisco@uol.com.br, egomesf@ufc.br
} 


\section{Introdução}

A salinidade é um dos estresses abióticos que mais limitam o crescimento e a produtividade agrícola (ZHU, 2001). Aproximadamente 23\% das terras cultivadas do mundo vêm enfrentando problemas de salinização (FAO, 2005), que é mais severo nas regiões áridas e semiáridas, onde as elevadas taxas evapotranspiratórias e as baixas precipitações pluviométricas, associadas ao manejo inadequado do solo e da água, têm contribuído para o surgimento de solos salinizados (FAGERIA; GHEYI, 1997).

A redução do crescimento causada pela salinidade é decorrente de seus efeitos osmóticos, tóxicos e nutricionais (MUNNS, 2002). O excesso de sais no solo altera a capacidade da planta em absorver, transportar e utilizar os íons necessários ao seu crescimento e desenvolvimento (PARIDA; DAS, 2005). O desequilíbrio nutricional causado pela salinidade decorre, principalmente, da redução na absorção de nutrientes essenciais à planta, devido à competição na absorção e transporte, às alterações estruturais na membrana, bem como à inibição da atividade de várias enzimas-chave do metabolismo (ARAGÃO et al., 2010; MANSOUR; SALAMA, 2004; PARIDA; DAS, 2005; ZHU, 2001).

Entre os nutrientes essenciais, o nitrogênio $(\mathrm{N})$, constituinte de muitas biomoléculas tais como proteínas, ácidos nucléicos, aminoácidos, pigmentos e vários hormônios vegetais, destaca-se por ser requerido em altas concentrações pelas plantas (WILLIAMS; MILLER, 2001). O N está disponível às plantas, principalmente, como uma mistura de amônio $\left(\mathrm{NH}_{4}^{+}\right)$e nitrato $\left(\mathrm{NO}_{3}^{-}\right)$, sendo este último a forma predominante e, dessa maneira, a principal fonte de $\mathrm{N}$ nos solos agricultáveis (MELONI et al., 2004; WILLIAMS; MILLER, 2001).

A carência de $\mathrm{N}$ é um dos principais fatores que limitam o crescimento das plantas em diferentes ecossistemas, sendo isso particularmente importante em condições de salinidade, pois solos salinos são, em geral, deficientes em N (ASHRAF; McNEILLY, 1994; WILLIAMS; MILLER, 2001). Além disso, a salinidade interfere na aquisição e na utilização do $\mathrm{N}$, podendo influenciar sua absorção, distribuição e assimilação, bem como na síntese de proteínas (ABD-EL BAKI et al., 2000; ARAGÃO et al., 2010; DEBOUBA et al., 2006; TABATABAEI, 2006). Os parâmetros de fotossíntese também podem ser afetados pelo status de N na planta, já que este nutriente é utilizado para a síntese de componentes do aparato fotossintético (RANJITH et al., 1995).

Alguns estudos têm demonstrado que uma fertilização nitrogenada adequada pode reduzir os efeitos deletérios da salinidade e promover o crescimento das plantas (BARHOUMI et al., 2010; EBERT et al., 2002). $\mathrm{O}$ papel do $\mathrm{N}$ no aumento da resistência das plantas à salinidade reside no fato de que o aumento do suprimento de $\mathrm{N}$ promove um maior acúmulo de compostos orgânicos nitrogenados (por exemplo, prolina, aminoácidos livres, glicinabetaína), que desempenham um importante papel no balanço osmótico celular, além de estabilizar estruturas subcelulares (membranas e proteínas) sob condições de estresse salino (PARIDA; DAS, 2005). Além disso, o $\mathrm{NO}_{3}$ , quando está em excesso, pode se acumular no vacúolo e também contribuir na redução do potencial osmótico da planta, favorecendo diretamente o ajustamento osmótico em condições de estresse salino (DING et al., 2010).

Dada a alta exigência de $\mathrm{N}$ pela maioria das gramíneas e a carência de estudos envolvendo a interação entre a salinidade e o $\mathrm{N}$ em sorgo sudão, objetivou-se avaliar, nesta espécie, o efeito da nutrição de $\mathrm{NO}_{3}^{-}$no crescimento, nas trocas gasosas e no acúmulo de solutos inorgânicos e orgânicos em plantas submetidas à salinidade.

\section{Material e métodos}

O experimento foi conduzido em casa de vegetação e as análises bioquímicas foram realizadas no Laboratório de Fisiologia Vegetal do Departamento de Bioquímica e Biologia Molecular, da Universidade Federal do Ceará. Sementes de sorgo sudão [Sorghum sudanense (Piper) Stapf] foram semeadas em copos plásticos contendo vermiculita umedecida com água destilada. Decorridos sete dias, as plântulas foram transferidas para bandejas de 10 L contendo solução nutritiva de Hoagland modificada (diluída 1:2), com $\mathrm{NO}_{3}^{-}$(única fonte de $\mathrm{N}$ ) nas concentrações de 0,5 ou $8,0 \mathrm{mM}$. Aos quatorze dias após a semeadura, foi iniciada a adição de $\mathrm{NaCl}$, que foi feita em parcelas de $25 \mathrm{mM}$ por dia até atingir a concentração final de $100 \mathrm{mM}$.

No mesmo dia da coleta (20 dias após o início da adição de $\mathrm{NaCl}$ ), no período de 08:00 às 10:00 h, foram mensurados os parâmetros de trocas gasosas (fotossíntese líquida, transpiração, condutância estomática e concentrações interna e externa de $\mathrm{CO}_{2}$ ) na porção mediana da primeira folha completamente expandida, a partir do ápice, utilizando-se, para isso, um analisador de gás no infravermelho (IRGA, ADC BioScientific Ltd., mod. LCi, Hoddesdon, UK) acoplado a uma fonte de radiação artificial (ADC BioScientific Ltd., Hoddesdon, UK) com intensidade de aproximadamente $1.200 \mu \mathrm{mol} \mathrm{m} \mathrm{m}^{-1} \mathrm{~s}^{-1}$.

Durante a coleta, as plantas foram divididas em folhas, colmos e raízes e, em seguida, determinaram-se a massa fresca dessas partes e a área foliar (LI-COR ${ }^{\circledR}$, mod. 
LI-3100, Lincoln, Nebraska, USA). As terceira e quarta folhas completamente expandidas, a partir da base, e o terço distal das raízes foram utilizados para a obtenção do suco celular. O restante do material coletado foi destinado à secagem em estufa com circulação forçada de ar a $60{ }^{\circ} \mathrm{C}$, por $48 \mathrm{~h}$ e após esse processo, determinou-se a massa seca (MS) das diferentes partes da planta, levandose em consideração a massa retirada inicialmente.

Em todas as determinações de solutos, foi utilizado o suco celular extraído dos tecidos de folhas e raízes, obtido pela maceração do material vegetal em almofariz, seguido de prensagem do macerado (envolto numa tela de náilon) com o auxílio de uma seringa descartável de $10 \mathrm{~mL}$. O líquido extraído foi, então, centrifugado a $12.000 \times \mathrm{g}$, por $10 \mathrm{~min}$, a $4{ }^{\circ} \mathrm{C}$, obtendo-se assim o sobrenadante (suco celular). Os teores de $\mathrm{Na}^{+}$e de $\mathrm{K}^{+}$foram determinados por fotometria de chama. Os teores de $\mathrm{Cl}^{-}$foram determinados segundo o método de Gaines et al. (1984), enquanto os teores de $\mathrm{NO}_{3}{ }^{-}$foram determinados através do método do ácido salicílico (CATALDO et al., 1975). Foram também analisados os teores de $\mathrm{N}$-aminossolúveis (YEMM; COCKING, 1955) e prolina (BATES et al., 1973).

$\mathrm{O}$ delineamento experimental foi o inteiramente casualizado, em esquema fatorial $2\left(\mathrm{NO}_{3}{ }^{-}\right.$a $0,5 \mathrm{mM}$ ou $8,0 \mathrm{mM}) \times 2(\mathrm{NaCl}$ a $0 \mathrm{mM}$ ou $100 \mathrm{mM})$, compreendendo cinco repetições, sendo cada repetição constituída por três plantas. Os resultados foram submetidos à análise de variância (ANOVA) e as médias comparadas pelo teste de Tukey a 5\% de significância. O programa utilizado para as análises estatísticas e a confecção dos gráficos foi o SigmaPlot 11.0.

\section{Resultados e discussão}

$\mathrm{O}$ efeito da nutrição com $\mathrm{NO}_{3}{ }^{-}$no crescimento das plantas de sorgo sudão sob estresse salino está apresentado na Tabela 1 e na Figura 1. Houve interação significativa entre salinidade e $\mathrm{NO}_{3}{ }^{-}$apenas na área foliar (AF) e na massa seca da parte aérea (MSPA) (TAB. 1). A salinidade reduziu esses parâmetros em ambos os tratamentos com $\mathrm{NO}_{3}^{-}$, mas essa redução foi mais pronunciada nas plantas nutridas com $\mathrm{NO}_{3}^{-}$a $8,0 \mathrm{mM}$. Apesar disso, as plantas deste tratamento, em ambas as condições de salinidade, apresentaram valores de AF e MSPA maiores que aqueles das plantas nutridas com $\mathrm{NO}_{3}^{-}$a $0,5 \mathrm{mM}$ (FIG. 1A e 1B). A massa seca das raízes (MSR) também foi reduzida pela salinidade, mas, diferentemente do que aconteceu com a AF e a MSPA, esse efeito não dependeu da concentração de $\mathrm{NO}_{3}{ }^{-}$do meio (TAB. 1 e FIG. 1C). Por fim, a salinidade e o $\mathrm{NO}_{3}^{-}$, bem como a interação entre eles, não interferiram de maneira significativa na relação MSPA/MSR das plantas de sorgo sudão (TAB. 1 e FIG. 1D).

Esses resultados mostram uma resposta típica de glicófitas à salinidade, as quais, na maioria das vezes, têm seu crescimento reduzido em razão desse estresse (GREENWAY; MUNNS, 1980). O aumento do suprimento de $\mathrm{N}$ foi capaz de promover o crescimento das plantas de sorgo sudão, tanto em condições controle quanto de salinidade (FIG. 1). Resultados semelhantes foram encontrados para outras espécies, tais como Helianthus annuus (CECHIN; FUMIS, 2004), Zea mays (FEIJÃO, 2007), Tamarix laxa (DING et al., 2010), Aeluropus litoralis e Catapodium rigidum (BARHOUMI et al., 2010). Contrariamente ao que foi observado neste trabalho, a salinidade $(\mathrm{NaCl}$ a $100 \mathrm{mM})$ reduziu a relação MSPA/MSR em dois genótipos de sorgo forrageiro (Sorghum bicolor) (LACERDA et al., 2001).

Dentre os parâmetros de trocas gasosas, a fotossíntese líquida $(A)$ foi o único afetado pela interação entre salinidade e $\mathrm{NO}_{3}^{-}$, no entanto, todos eles foram influenciados pela concentração de $\mathrm{NO}_{3}^{-}$no meio de cultivo (TAB. 1). A salinidade não teve efeito sobre a condutância estomática $\left(g_{s}\right)$ (TAB.1; FIG. 2A), mas causou a redução da $A$ nas plantas tratadas com $\mathrm{NO}_{3}^{-}$a $8,0 \mathrm{mM}$ (FIG. 2B). A inibição da $A$ pela salinidade parece estar mais relacionada com os danos no aparelho fotossintético ou no sistema enzimático de fixação de $\mathrm{CO}_{2}$ do que com as limitações estomáticas, já que não foram observadas alterações na condutância estomática, em função da

Tabela 1 - Valores do teste $F$ para a área foliar (AF), massa seca da parte aérea (MSPA) e das raízes (MSR), relação MSPA/MSR, condutância estomática $\left(g_{s}\right)$, fotossíntese líquida $(A)$, transpiração $(E)$ e relação entre as concentrações interna e externa de $\mathrm{CO}_{2}\left(C / C_{o}\right)$ de plantas de sorgo sudão cultivadas em solução nutritiva com $\mathrm{NO}_{3}^{-}$a 0,5 ou $8,0 \mathrm{mM}$ e sob condições controle ou de estresse salino

\begin{tabular}{ccccccccc}
\hline Fontes de variação & AF & MSPA & MSR & MSPA/MSR & $g_{s}$ & $A$ & $E$ & $C_{i} / C_{o}$ \\
\hline Salinidade (S) & $228,19^{* * *}$ & $229,12^{* * *}$ & $130,16^{* * *}$ & $4,66^{\mathrm{ns}}$ & $0,39^{\mathrm{ns}}$ & $18,84^{* * *}$ & $9,43^{*}$ & $2,93^{\mathrm{ns}}$ \\
Nitrato (N) & $71,83^{* * *}$ & $78,93^{* * *}$ & $14,81^{* * *}$ & $1,84^{\mathrm{ns}}$ & $27,24^{* * *}$ & $155,39^{* * *}$ & $76,91^{* * *}$ & $12,61^{*}$ \\
S x N & $19,31^{* * *}$ & $12,40^{* *}$ & $1,78^{\mathrm{ns}}$ & $3,21^{\mathrm{ns}}$ & $0,80^{\mathrm{ns}}$ & $44,81^{* * *}$ & $0,34^{\mathrm{ns}}$ & $0,47^{\mathrm{ns}}$ \\
\hline
\end{tabular}

${ }^{*} P \leq 0,05 ;{ }^{* *} P \leq 0,01 ;{ }^{* * *} P \leq 0,001 ;$ " ns não significativo 


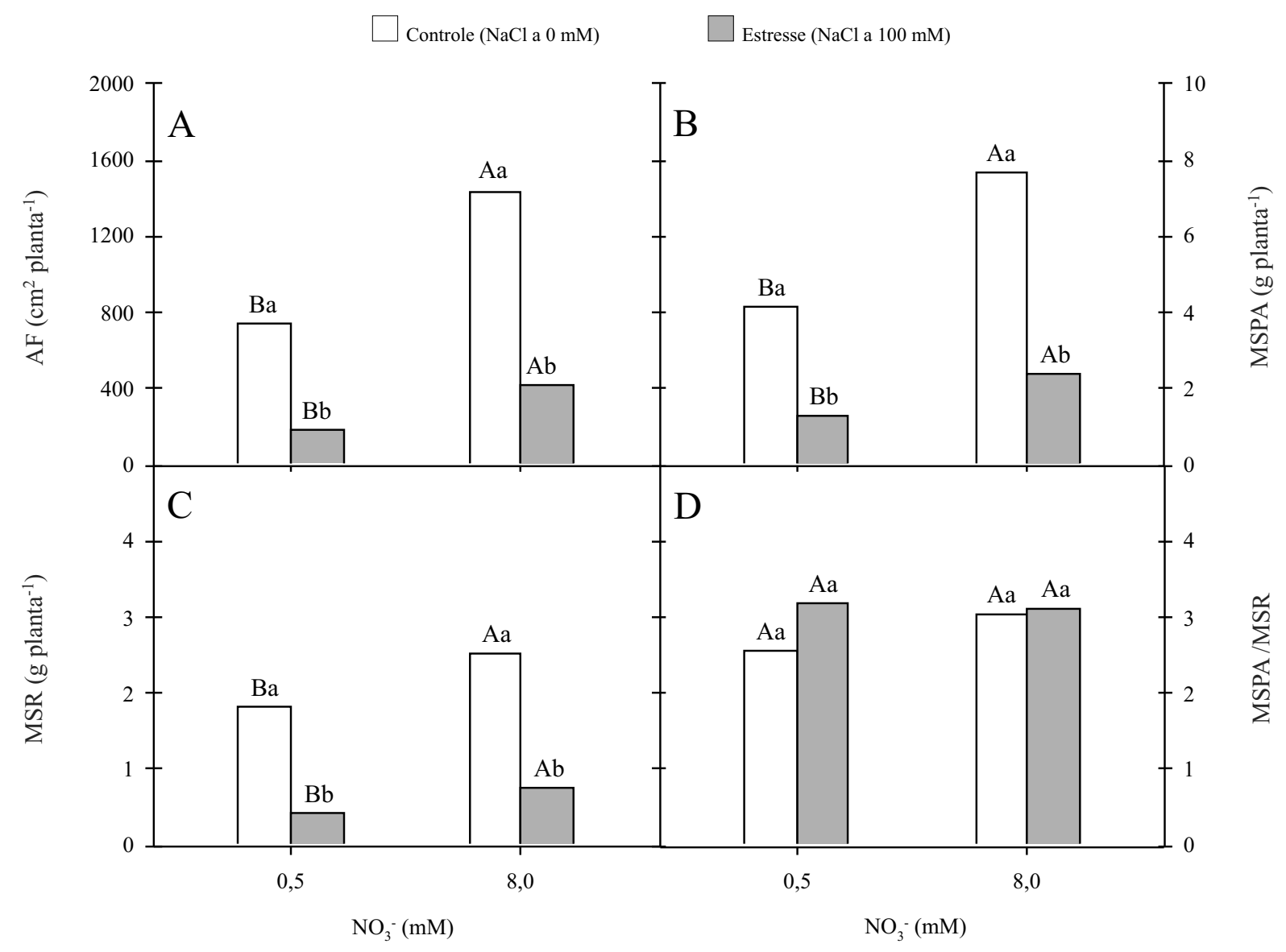

Figura 1 - Área foliar (AF, A), massa seca da parte aérea (MSPA, B) e das raízes (MSR, C) e relação MSPA/MSR (D) de plantas de sorgo sudão cultivadas em solução nutritiva com $\mathrm{NO}_{3}^{-}$a 0,5 ou $8,0 \mathrm{mM}$ e sob condições controle ou de estresse salino. Colunas seguidas pelas mesmas letras minúsculas em um mesmo nível de $\mathrm{NO}_{3}^{-}$ou maiúsculas em um mesmo nível de salinidade não diferem significativamente entre si pelo teste de Tukey $(P \leq 0,05)$

salinidade (PARIDA; DAS, 2005). O estresse salino reduziu a transpiração $(E)$ das plantas de sorgo sudão em ambos os tratamentos com $\mathrm{NO}_{3}^{-}$, porém, não afetou a relação entre as concentrações interna e externa de $\mathrm{CO}_{2}$ $\left(C / C_{o}\right)$ (FIG. 2C e 2D).

Como visto na Figura 2, todos os parâmetros de trocas gasosas foram maiores nas plantas nutridas com $\mathrm{NO}_{3}^{-}$a $8,0 \mathrm{mM}$, em comparação àqueles de plantas nutridas com $0,5 \mathrm{mM}$. Isso pode explicar parcialmente o melhor crescimento das plantas de sorgo sudão submetidas à maior concentração de $\mathrm{NO}_{3}^{-}$. Vários trabalhos mostram uma correlação positiva entre a taxa fotossintética e a nutrição de N (CECHIN; FUMIS, 2004; RANJITH et al., 1995). Em cana-de-açúcar, uma reduzida disponibilidade de $\mathrm{N}$ levou a uma menor concentração desse nutriente nas folhas e a uma menor atividade das enzimas fotossintéticas, reduzindo, conseqüentemente, a $A$ (RANJITH et al., 1995), mas isso não é uma resposta geral das plantas, pois Tabatabaei (2006) observou que o aumento da concentração de $\mathrm{N}$ no meio de cultivo induziu a redução da $g_{\text {s, }} A$ e $E$ em oliveira.

Com exceção do $\mathrm{Cl}^{-}$, todos os íons estudados tiveram suas concentrações afetadas pela interação entre salinidade e $\mathrm{NO}_{3}^{-}$, tanto nas folhas quanto nas raízes (TAB. 2). As concentrações de $\mathrm{Na}^{+}$aumentaram significativamente, em função da salinidade, nas folhas e nas raízes das plantas tratadas com ambas as concentrações de $\mathrm{NO}_{3}^{-}$(FIG. 3A e 3B). Em condições de salinidade, as folhas das plantas nutridas com $\mathrm{NO}_{3}^{-}$a $0,5 \mathrm{mM}$ foram as que mais acumularam $\mathrm{Na}^{+}$, enquanto que nas raízes, o maior acúmulo deste íon ocorreu nas plantas nutridas com $\mathrm{NO}_{3}^{-}$a $8,0 \mathrm{mM}$ (FIG. $3 \mathrm{~A}$ e $3 \mathrm{~B}$ ), indicando que o aumento da concentração de $\mathrm{NO}_{3}{ }^{-}$contribuiu para a redução da translocação de $\mathrm{Na}^{+}$para a parte aérea. Resultado semelhante já havia sido observado por Ebert et al. (2002) em goiabeira. O aumento do suprimento de $\mathrm{NO}_{3}^{-}$às plantas da halófita 
T. laxa, em condições de salinidade, reduziu os teores de $\mathrm{Na}^{+}$tanto na parte aérea quanto na raiz (DING et al., 2010), mas em milho, a nutrição de $\mathrm{NO}_{3}^{-}$não influenciou os teores de $\mathrm{Na}^{+}$(FEIJÃO, 2007).
$\mathrm{O}$ aumento da disponibilidade de $\mathrm{NO}_{3}{ }^{-}$proporcionou o acúmulo de $\mathrm{K}^{+}$nas folhas das plantas sob condições salinas, porém, nas condições controle, nenhum efeito do $\mathrm{NO}_{3}^{-}$foi observado (FIG. 3C). Nas raízes das plantas sob salinidade,

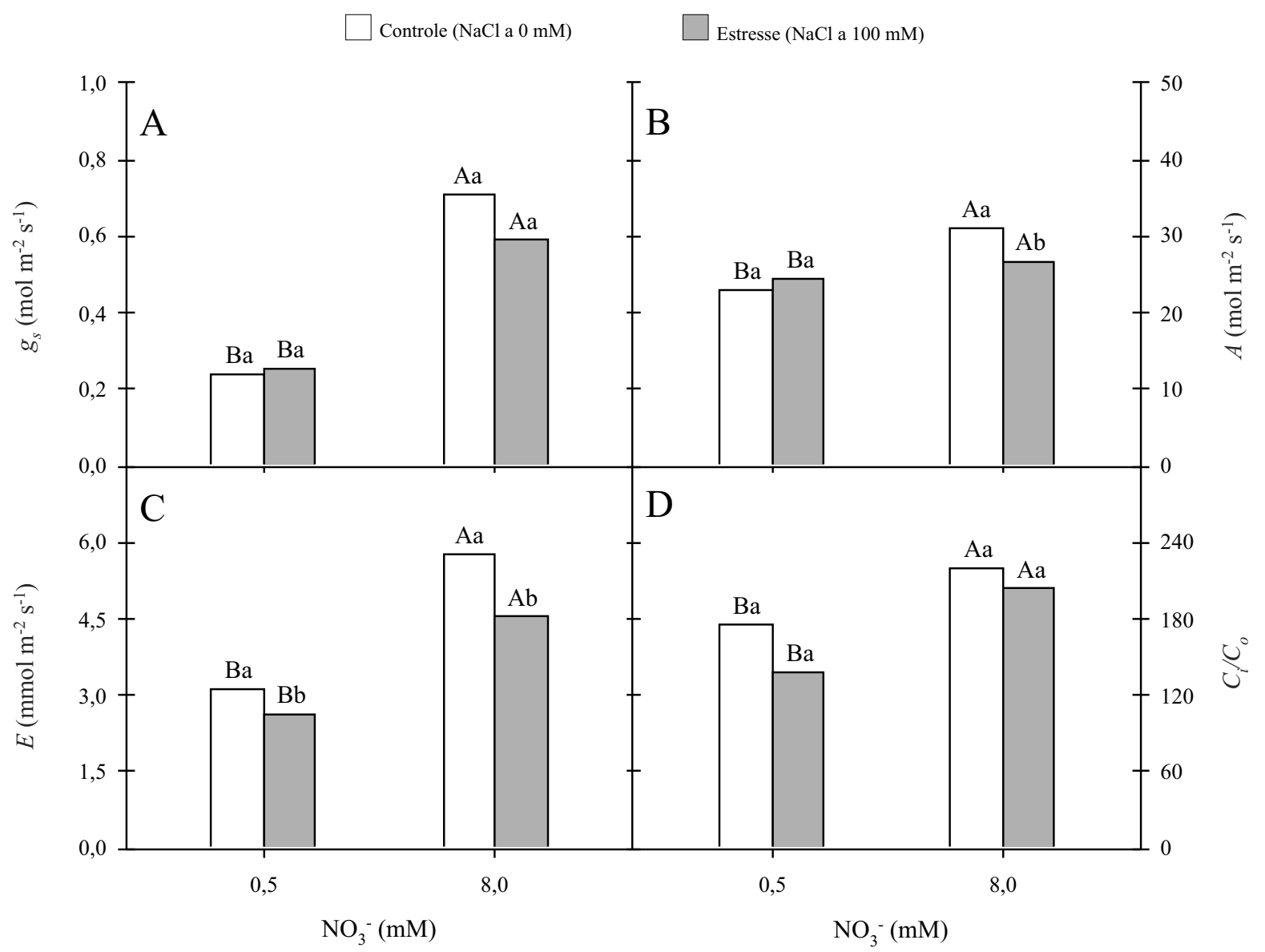

Figura 2 - Condutância estomática $\left(g_{s}, \mathrm{~A}\right)$, fotossíntese líquida $(A, \mathrm{~B})$, transpiração $(E, \mathrm{C})$ e relação entre a concentração interna e externa de $\mathrm{CO}_{2}\left(C / C_{o}\right)$ de plantas de sorgo sudão cultivadas em solução nutritiva com $\mathrm{NO}_{3}^{-}$a 0,5 ou $8,0 \mathrm{mM}$ e sob condições controle ou de estresse salino. Colunas seguidas pelas mesmas letras minúsculas em um mesmo nível de $\mathrm{NO}_{3}{ }^{-}$ou maiúsculas em um mesmo nível de salinidade não diferem significativamente entre si pelo teste de Tukey $(P \leq 0,05)$

Tabela 2 - Valores do teste $F$ para as concentrações de $\mathrm{Na}^{+}, \mathrm{K}^{+}, \mathrm{Cl}^{-}$e $\mathrm{NO}_{3}^{-}$em folhas e raízes de plantas de sorgo sudão cultivadas em solução nutritiva com $\mathrm{NO}_{3}^{-}$a 0,5 ou $8,0 \mathrm{mM}$ e sob condições controle ou de estresse salino

\begin{tabular}{|c|c|c|c|c|c|c|c|c|}
\hline \multirow{2}{*}{$\begin{array}{c}\text { Fontes de } \\
\text { variação }\end{array}$} & \multicolumn{4}{|c|}{ Folhas } & \multicolumn{4}{|c|}{ Raízes } \\
\hline & $\mathrm{Na}^{+}$ & $\mathrm{K}^{+}$ & $\mathrm{Cl}^{-}$ & $\mathrm{NO}_{3}^{-}$ & $\mathrm{Na}^{+}$ & $\mathrm{K}^{+}$ & $\mathrm{Cl}^{-}$ & $\mathrm{NO}_{3}^{-}$ \\
\hline Salinidade (S) & $231,17 * * *$ & $9,84 * *$ & $133,23 * * *$ & $23,80 * * *$ & $452,90 * * *$ & $76,91 * * *$ & $14,98 * * *$ & $32,28 * * *$ \\
\hline Nitrato $(\mathrm{N})$ & $30,06 * * *$ & $1,56^{\mathrm{ns}}$ & $12,56 * *$ & $81,40 * * *$ & $5,16^{*}$ & $0,03^{\mathrm{ns}}$ & $16,63 * * *$ & $722,78 * * *$ \\
\hline $\mathrm{S} \times \mathrm{N}$ & $30,19 * * *$ & $7,71 *$ & $0,0008^{\text {ns }}$ & $50,62 * * *$ & $4,99 *$ & $8,85 * *$ & $22,03^{\mathrm{ns}}$ & $95,04 * * *$ \\
\hline
\end{tabular}

${ }^{*} P \leq 0,05 ;{ }^{* *} P \leq 0,01 ;{ }^{* * *} P \leq 0,001 ;{ }^{\text {ns }}$ não significativo 


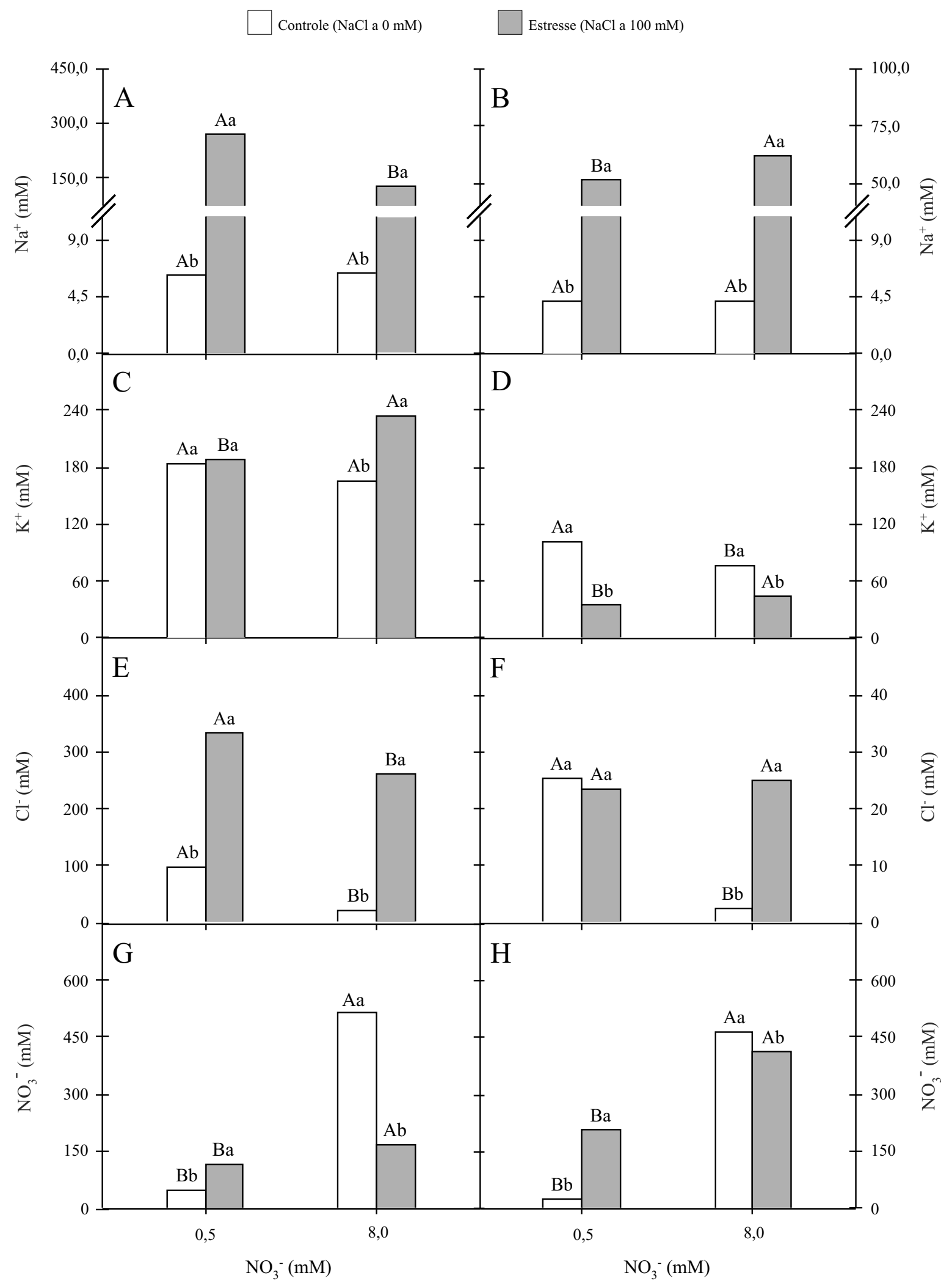

Figura 3 - Teores de $\mathrm{Na}^{+}, \mathrm{K}^{+}, \mathrm{Cl}^{-}$e $\mathrm{NO}_{3}^{-}$em folhas (A, C, E e G) e raízes (B, D, F e H) de plantas de sorgo sudão cultivadas em solução nutritiva com $\mathrm{NO}_{3}^{-}$a 0,5 ou $8,0 \mathrm{mM}$ e sob condições controle ou de estresse salino. Colunas seguidas pelas mesmas letras minúsculas em um mesmo nível de $\mathrm{NO}_{3}^{-}$ou maiúsculas em um mesmo nível de salinidade não diferem significativamente entre si pelo teste de Tukey $(P \leq 0,05)$ 
a concentração de $\mathrm{K}^{+}$também foi maior nas plantas nutridas com $\mathrm{NO}_{3}^{-}$a $8,0 \mathrm{mM}$, apesar de o estresse salino ter reduzido a concentração de $\mathrm{K}^{+}$em ambos os tratamentos de $\mathrm{NO}_{3}^{-}$ (FIG. 3D). A influência do $\mathrm{NO}_{3}^{-}$sobre os teores de $\mathrm{K}^{+}$é bastante contraditória. Ebert et al. (2002) mostraram que o aumento de $\mathrm{NO}_{3}{ }^{-}$no meio de cultivo elevou os teores de $\mathrm{K}^{+}$ em folhas de goiabeira sob condições salinas, enquanto que em milho (FEIJÃO, 2007) e T. laxa (DING et al., 2010) não foi observada influência do $\mathrm{NO}_{3}^{-}$nesses teores, tanto em condições controle como de salinidade.

A salinidade aumentou a concentração de $\mathrm{Cl}^{-}$nas folhas das plantas de ambos os tratamentos de $\mathrm{NO}_{3}^{-}$, bem como nas raízes das plantas tratadas com $\mathrm{NO}_{3}^{-}$a $8,0 \mathrm{mM}$ (FIG. 3E e $3 \mathrm{~F}$ ). Houve uma menor concentração de $\mathrm{Cl}^{-}$nas folhas das plantas tratadas com $\mathrm{NO}_{3}^{-}$a $8,0 \mathrm{mM}$, tanto em condições controle quanto de estresse salino (FIG. 3E), mostrando que uma adequada nutrição de $\mathrm{NO}_{3}$ - pode reduzir a translocação de íons tóxicos para as folhas e aumentar a resistência das plantas à salinidade, uma vez que $\mathrm{Na}^{+} \mathrm{e} \mathrm{Cl}^{-}$são os íons inorgânicos que mais alteram a funcionalidade das enzimas (BARHOUMI et al., 2010). Em milho, houve uma correlação negativa entre o acúmulo de $\mathrm{Cl}^{-}$e $\mathrm{NO}_{3}^{-}$(FEIJÃO, 2007).

Nos dois órgãos estudados, as maiores concentrações de $\mathrm{NO}_{3}^{-}$foram observadas nas plantas cultivadas com $\mathrm{NO}_{3}^{-}$ a $8,0 \mathrm{mM}$, tanto em condições controle quanto de estresse salino, e, além disso, a concentração de $\mathrm{NO}_{3}^{-}$variou diferentemente com a salinidade, entre os tratamentos de $\mathrm{NO}_{3}^{-}$(FIG. $3 \mathrm{G}$ e $3 \mathrm{H}$ ). Nas plantas nutridas com a baixa concentração de $\mathrm{NO}_{3}^{-}$, os teores deste íon em folhas e raízes foram aumentados pela salinidade. Isso pode estar associado ao acúmulo de $\mathrm{NO}_{3}^{-}$nos vacúolos devido à redução na atividade da redutase do nitrato (NR), enzima que catalisa o primeiro passo da assimilação de $\mathrm{NO}_{3}^{-}$. A atividade da NR é alterada tanto pela concentração deste íon no meio de cultivo quanto pelo $\mathrm{NaCl}$ (ARAGÃO et al., 2010; DEBOUBA et al., 2006). Dessa maneira, ocorreu, provavelmente, um desequilíbrio entre as taxas de absorção e assimilação de $\mathrm{NO}_{3}^{-}$, já observado anteriormente em condições de salinidade (ABD-EL BAKI et al., 2000). Contudo, em plantas cultivadas no meio com a mais alta concentração de
$\mathrm{NO}_{3}^{-}$(8,0 mM), foi observada uma redução do acúmulo de $\mathrm{NO}_{3}^{-}$em condições de salinidade (FIG. $3 \mathrm{G}$ e $3 \mathrm{H}$ ). $\mathrm{O}$ efeito negativo da salinidade na absorção de $\mathrm{NO}_{3}$ - já foi relatado em várias espécies com tolerância diferencial ao estresse salino, sendo isto devido à competição direta entre os íons $\mathrm{Cl}^{-} \mathrm{e} \mathrm{NO}_{3}^{-}$ pelo mesmo transportador ou às alterações na integridade da membrana (ARAGÃO et al., 2010; BARHOUMI et al., 2010; MANSOUR; SALAMA, 2004).

O efeito do $\mathrm{NO}_{3}{ }^{-}$na concentração de $\mathrm{N}$-aminossolúveis e prolina em folhas e raízes de plantas de sorgo sudão sob estresse salino está apresentado na Tabela 3. A interação entre salinidade e $\mathrm{NO}_{3}^{-}$foi significativa para todos os parâmetros estudados, à exceção da concentração de $\mathrm{N}$-aminossolúveis nas raízes (TAB. 3). O estresse salino aumentou os teores de $\mathrm{N}$-aminossolúveis em ambos os órgãos estudados e, nas raízes, houve um maior acúmulo deste soluto nas plantas nutridas com $\mathrm{NO}_{3}^{-}$a $8,0 \mathrm{mM}$ (FIG. 4A e 4B). A concentração de prolina nas folhas aumentou com a salinidade, principalmente nas plantas nutridas com $\mathrm{NO}_{3}^{-}$ a 0,5 mM (FIG. 4C). Já nas raízes, a salinidade não alterou os teores deste soluto nas plantas nutridas com $0,5 \mathrm{mM}$ de $\mathrm{NO}_{3}^{-}$, no entanto, na maior concentração de $\mathrm{NO}_{3}^{-}$observouse um maior acúmulo de prolina nas raízes das plantas submetidas ao estresse salino (FIG. 4D). O acúmulo de prolina e aminoácidos livres em tecidos de plantas sob salinidade é uma resposta comum ao estresse salino (AZEVEDO NETO et al., 2004; LACERDA et al., 2001). Diversas funções são propostas para estes compostos em condições de estresse, das quais podemos destacar: ajustamento osmótico, proteção de macromoléculas, fonte de $\mathrm{N}$ e energia, manutenção do $\mathrm{pH}$ celular, além de atenuar os efeitos do estresse oxidativo por eliminar radicais livres (PARIDA; DAS, 2005). Neste estudo, não se pôde precisar quais funções estes compostos exerceram nas plantas de sorgo sudão, porém, o maior aumento de suas concentrações nas raízes das plantas nutridas com $\mathrm{NO}_{3}^{-}$ a $8,0 \mathrm{mM}$ e sob estresse salino, em comparação àquelas nutridas com $\mathrm{NO}_{3}^{-}$a $0,5 \mathrm{mM}$, contribuiu, provavelmente, para que essas plantas superassem os efeitos deletérios da salinidade (FIG. 4B e 4D).

Tabela 3 - Valores do teste $F$ para as concentrações de N-aminossolúveis e prolina em folhas e raízes de plantas de sorgo sudão cultivadas em solução nutritiva com $\mathrm{NO}_{3}^{-}$a 0,5 ou $8,0 \mathrm{mM}$ e sob condições controle ou de estresse salino

\begin{tabular}{ccccc}
\hline \multirow{2}{*}{ Fontes de variação } & \multicolumn{2}{c}{ Folhas } & \multicolumn{2}{c}{ Raízes } \\
\cline { 2 - 5 } & N-aminossolúveis & Prolina & N-aminossolúveis & Prolina \\
\hline Salinidade (S) & $261,45^{* * *}$ & $736,06^{* * *}$ & $52,88^{* * *}$ & $23,65^{* * *}$ \\
Nitrato (N) & $45,93^{* * *}$ & $6,74^{*}$ & $124,89^{* * *}$ & $0,04^{\mathrm{ns}}$ \\
S x N & $67,44^{* * *}$ & $14,01^{* *}$ & $0,11^{\mathrm{ns}}$ & $12,55^{* *}$ \\
\hline
\end{tabular}

${ }^{*} P \leq 0,05 ;{ }^{* *} P \leq 0,01 ;{ }^{* * *} P \leq 0,001 ;{ }^{\text {ns }}$ não significativo 


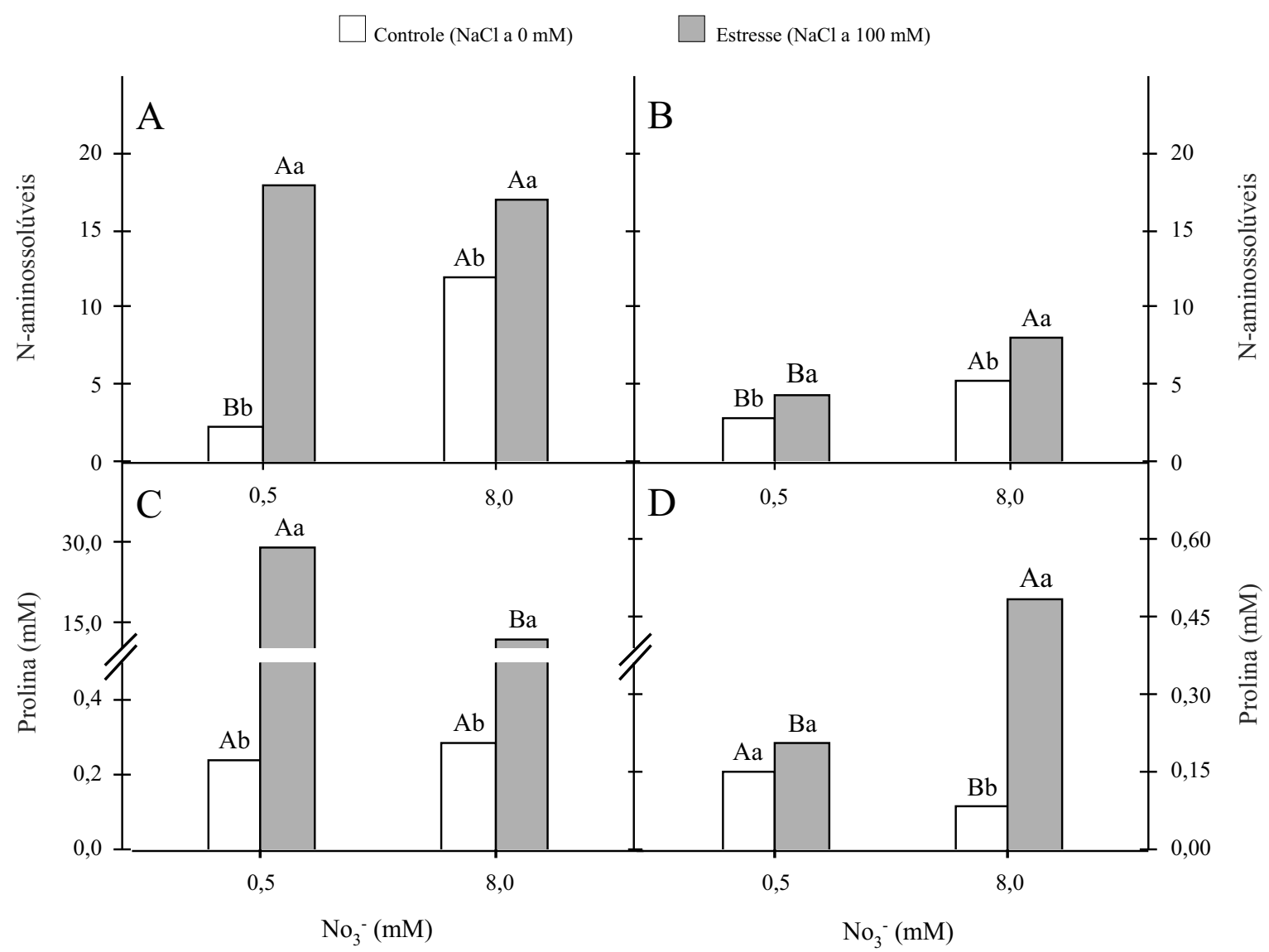

Figura 4 - Teores de $\mathrm{N}$-aminossolúveis e prolina em folhas (A e C) e raízes (B e D) de plantas de sorgo sudão cultivadas em solução nutritiva com $\mathrm{NO}_{3}^{-}$a 0,5 ou $8,0 \mathrm{mM}$ e sob condições controle ou de estresse salino. Colunas seguidas pelas mesmas letras minúsculas em um mesmo nível de $\mathrm{NO}_{3}^{-}$ou maiúsculas em um mesmo nível de salinidade não diferem significativamente entre si pelo teste de Tukey $(\mathrm{P} \leq 0,05)$

\section{Conclusões}

1. A nutrição com $\mathrm{NO}_{3}^{-}$a $8,0 \mathrm{mM}$ foi capaz de reduzir os efeitos deletérios da salinidade nas plantas de sorgo sudão, fato este demonstrado pelo aumento da fotossíntese e pela redução da translocação de íons $\mathrm{Na}^{+}$ e $\mathrm{Cl}^{-}$para as folhas nessas condições, resultando em um melhor crescimento destas plantas, em comparação àquelas nutridas com $\mathrm{NO}_{3}^{-}$a $0,5 \mathrm{mM}$;

2. O aumento da concentração de $\mathrm{N}$-aminossolúveis e prolina nas raízes das plantas de sorgo sudão ocasionado pela maior disponibilidade de $\mathrm{N}$, contribuiu, provavelmente, para o melhor desempenho destas plantas frente à salinidade.

\section{Agradecimentos}

Ao Conselho Nacional de Desenvolvimento Científico e Tecnológico (CNPq), à Fundação Cearense de Apoio ao Desenvolvimento Científico e Tecnológico (FUNCAP) e ao Instituto Nacional de Ciência e Tecnologia em Salinidade (INCTSal) pela concessão de bolsas e de recursos financeiros indispensáveis à realização deste trabalho de pesquisa.

\section{Referências}

ABD-EL BAKI, G. K. et al. Nitrate reductase in Zea mays L. under salinity. Plant, Cell and Environment, v. 23, n. 05, p. $515-521,2000$.

ARAGÃO, R. M. et al. Absorção, fluxo no xilema e assimilação do nitrato em feijão-caupi submetido à salinidade. Revista Ciência Agronômica, v. 41, n. 01, p. 100-106, 2010.

ASHRAF, M.; McNEILLY, T. Responses of three arid zone grasses to $\mathrm{N}$ deficiency: A greenhouse study. Arid Soil Research and Rehabilitation, v. 08, n. 02, p. 125-136, 1994.

AZEVEDO NETO, A. D. et al. Effects of salt stress on plant growth, stomatal response and solute accumulation of different 
maize genotypes. Brazilian Journal of Plant Physiology, v. 16, n. 01, p. 31-38, 2004.

BARHOUMI, Z. et al. Nitrogen and $\mathrm{NaCl}$ salinity effects on the growth and nutrient acquisition of the grasses Aeluropus littoralis, Catapodium rigidum, and Brachypodium distachyum. Journal of Plant Nutrition and Soil Science, v. 173, n. 01, p. 149-157, 2010.

BATES, L. S.; WALDREN, R. P.; TEARE, I. D. Rapid determination of free proline for water-stress studies. Plant and Soil, v. 39, n. 01, p. 205-207, 1973.

CATALDO, D. A. et al. Rapid colorimetric determination of nitrate in plant tissue by nitration of salicylic. Communications in Soil Science and Plant Analysis, v. 06, n. 01, p. 71-80, 1975.

CECHIN, I.; FUMIS, T. F. Effect of nitrogen supply on growth and photosynthesis of sunflower plants grown in the greenhouse. Plant Science, v. 166, n. 05, p. 1379-1385, 2004.

DEBOUBA, M. et al. Salinity-induced tissue-specific diurnal changes in nitrogen assimilatory enzymes in tomato seedlings grown under high or low nitrate medium. Plant Physiology and Biochemistry, v. 44, n. 05-06, p. 409-419, 2006.

DING, X. et al. Effects of $\mathrm{NO}_{3}^{-}-\mathrm{N}$ on the growth and salinity tolerance of Tamarix laxa Willd. Plant and Soil, v. 331, n. 01-02, p. 57-67, 2010.

EBERT, G. et al. Ameliorating effects of $\mathrm{Ca}\left(\mathrm{NO}_{3}\right)_{2}$ on growth, mineral uptake and photosynthesis of $\mathrm{NaCl}$-stressed guava seedlings (Psidium guajava L.). Scientia Horticulturae, v. 93, n. 02, p. 125-135, 2002.

FAGERIA, N. K.; GHEYI, H. R. Melhoramento genético das culturas e seleção de cultivares. In: GHEYI, H. R., QUEIROZ, J. E., MEDEIROS, J. F. Manejo e controle da salinidade na agricultura irrigada. Campina Grande: UFPB, SBEA, 1997, p. 363-383.

FAO. Global network on integrated soil management for sustainable use of salt-affected soils. Rome: FAO Land and Plant Nutrition Management Service, 2005. Disponível em: $<\mathrm{http}: / /$ www.fao.org/ag/AGL/agll/spush>. Acesso em: 10 jun. 2010.

FEIJÃO, A. R. Efeitos do nitrato no crescimento, no acúmulo de íons e nas trocas gasosas de plantas de milho (Zea mays $\mathbf{L}$.) submetidas à salinidade. 2007. $69 \mathrm{f}$. Monografia (Bacharelado em Ciências Biológicas) - Universidade Federal do Ceará, Fortaleza.
GAINES, T. P.; PARKER, M. B.; GASCHO, G. J. Automated determination of chlorides in soil and plant tissue by sodium nitrate. Agronomy Journal, v. 76, n. 03, p. 371-374, 1984.

GREENWAY, H.; MUNNS, R. Mechanisms of salt tolerance in nonhalophytes. Annual Review of Plant Physiology, v. 31, p. 149-190, 1980 .

LACERDA, C. F. et al. Plant growth and solute accumulation and distribution in two sorghum genotypes, under $\mathrm{NaCl}$ stress. Revista Brasileira de Fisiologia Vegetal, v. 13, n. 03, p. 270-284, 2001.

MANSOUR, M. M. F.; SALAMA, K. H. A. Cellular basis of salinity tolerance in plants. Environmental and Experimental Botany, v. 52, n. 02, p. 113-122, 2004

MELONI, D. A. et al. The effects of salt stress on growth, nitrate reduction and proline and glycinebetaine accumulation in Prosopis alba. Brazilian Journal Plant Physiology, v. 16, n. 01, p.39-46, 2004.

MUNNS, R. Comparative physiology of salt and water stress. Plant, Cell and Environment, v. 25, n. 02, p. 239-250, 2002.

PARIDA, A. K.; DAS, A. B. Salt tolerance and salinity effects on plants: a review. Ecotoxicology and Environment Safety, v. 60, n. 03, p. 324-349, 2005.

RANJITH, S. A. et al. Partitioning of carboxylase activity in nitrogen-stressed sugarcane and its relationship to bundle sheath leakiness to $\mathrm{CO}_{2}$, photosynthesis and carbon isotope discrimination. Australian Journal of Plant Physiology, v. 22, n. 06, p. 903-911, 1995.

TABATABAEI, S. J. Effects of salinity and $\mathrm{N}$ on the growth, photosynthesis and $\mathrm{N}$ status of olive (Olea europaea $\mathrm{L}$.) trees. Scientia Horticulturae, v. 108, n. 04, p. 432-438, 2006.

WILLIAMS, L. E.; MILLER, A. J. Transporters responsible for the uptake and partitioning of nitrogenous solutes. Annual Review of Plant Physiology and Plant Molecular Biology, v. 52, p. 659-688, 2001.

YEMM, E. W.; COCKING, E. C. The determination of aminoacids with ninhydrin. Analyst, v. 80, n. 948, p. 209-213, 1955.

ZHU, J. K. Plant salt tolerance. Trends Plant Science, v. 6, n. 02 , p. $66-71,2001$ 